\title{
Prevalence and Genotype Distribution of Hepatitis C Virus Infection among Patients with Type 2 Diabetes Mellitus
}

\author{
Fatemeh Farshadpour ${ }^{\mathrm{a}}$ Reza Taherkhani ${ }^{\mathrm{a}} \quad$ Mohammad Reza Ravanbod $^{\mathrm{b}}$ \\ Seyed Sajjad Eghbali ${ }^{\mathrm{a}}$ \\ aThe Persian Gulf Tropical Medicine Research Center, Bushehr University of Medical Sciences, Bushehr, Iran; \\ ${ }^{b}$ Department of Internal Medicine, School of Medicine, Bushehr University of Medical Sciences, Bushehr, Iran
}

\section{Significance of the Study}

- In this study, the prevalence of hepatitis C virus (HCV) infection was determined among type 2 diabetes mellitus (DM) patients in southern Iran. Patients with type 2 DM had a high prevalence of HCV infection with genotype $3 \mathrm{a}$, and this HCV seropositivity was independent of biochemical parameters. Therefore, screening of all type $2 \mathrm{DM}$ patients for HCV infection should be recommended to prevent the serious consequences associated with the coexistence of these two chronic diseases.

\section{Keywords}

Hepatitis C virus · Diabetes mellitus · Genotype ·

Prevalence $\cdot$ Iran

\begin{abstract}
Objective: This study was conducted to determine the prevalence and genotype distribution of hepatitis $C$ virus (HCV) infection among patients with type 2 diabetes mellitus (DM). Subjects and Methods: We included 556 consecutive patients with confirmed type 2 DM attending the Diabetic Clinic of the Bushehr University of Medical Sciences and 733 nondiabetic subjects as controls. Serum levels of fasting blood sugar (FBS), alanine transaminase (ALT), aspartate transaminase (AST), total cholesterol (TCH), and triglycerides (TG) were measured by enzymatic colorimetric methods, and the presence of anti-HCV antibodies was determined by en-
\end{abstract}

\begin{tabular}{ll}
\hline KARGER & $\begin{array}{l}\text { (c) 2018 The Author(s) } \\
\text { Published by S. Karger AG, Basel }\end{array}$ \\
E-Mail karger@karger.com & $\begin{array}{l}\text { This is an Open Access article licensed under the Creative Commons } \\
\text { Attribution-NonCommercial-4.0 International License (CC BY-NC) } \\
\text { (http://www.karger.com/Services/OpenAccessLicense), applicable to } \\
\text { the online version of the article only. Usage and distribution for } \\
\text { commercial purposes requires written permission. }\end{array}$
\end{tabular}

zyme-linked immunosorbent assay. Semi-nested reverse transcriptase-polymerase chain reaction (RT-PCR) followed by sequencing was performed on all anti-HCV-seropositive samples. Data were analyzed using the Statistical Package for the Social Sciences 17, and descriptive statistics, $X^{2}$ test, Fisher exact test, and the Student $t$ test were used for analysis. Results: The seroprevalence of HCV in the diabetic patients was $1.98 \%$ (11/556), which was higher than HCV prevalence among the nondiabetic controls $(4 / 733,0.54 \%)(p=$ 0.032). No significant differences in ALT, AST, FBS, TG, and $\mathrm{TCH}$ levels were found between the HCV-seropositive and $\mathrm{HCV}$-seronegative diabetic patients, although HCV-seropositive diabetic patients tended to have higher ALT, AST, and TCH levels, but lower TG and FBS levels than HCV-seronegative patients. In logistic regression analysis, only AST levels were significantly associated with HCV seropositivity among diabetic patients. The AST level of 41-80 IU/L was the only 
significant predictive variable for HCV seropositivity in the diabetic patients (odds ratio, 4.89; 95\% Cl: 1.06-22.49; $p=$ 0.041). Of the $11 \mathrm{HCV}$-seropositive diabetic patients, 10 (91\%) had HCV viremia with genotype 3a. Conclusion: Patients with type $2 \mathrm{DM}$ had a higher prevalence of HCV infection than controls, and HCV seropositivity was independent of biochemical parameters.

(c) 2018 The Author(s)

Published by S. Karger AG, Basel

\section{Introduction}

Type 2 diabetes mellitus (DM) is one of the most common chronic noncommunicable diseases characterized by hyperglycemia due to impaired glucose disposal resulting from defects in insulin secretory responses and action [1]. Long-term hyperglycemia may eventually lead to renal failure, loss of vision, cardiovascular diseases, foot ulcers, and sexual dysfunction in a proportion of cases over time [1]. In 2014, the global prevalence of diabetes among adults aged $\geq 18$ years was approximately $8.5 \%$, and about 422 million people were diabetic worldwide [2]. Diabetes was responsible for approximately $1.5 \mathrm{mil}-$ lion deaths in 2012 [2]. Type 2 DM accounted for $90-95 \%$ of all diabetic cases [3].

The development of type $2 \mathrm{DM}$ is a multifactorial process related to several risk factors, which include obesity, physical inactivity, aging, genetic predisposition, urbanization, and viral infections [4-6]. Among viral infections, hepatitis $\mathrm{C}$ virus (HCV) infection was ascribed a possible role in the onset of type $2 \mathrm{DM}$ because of the ability of $\mathrm{HCV}$ to induce insulin resistance, the higher prevalence of type $2 \mathrm{DM}$ in $\mathrm{HCV}$-infected patients compared to noninfected cases, as well as improvement in insulin resistance following antiviral therapy [7-9].

$\mathrm{HCV}$ is the causative agent of hepatitis $\mathrm{C}$ infection, affecting approximately $3 \%$ of the world population, while $85 \%$ (about 170 million individuals worldwide) are chronically infected with HCV $[4,5]$. Chronic HCV infection might lead to liver failure, cirrhosis, or hepatocellular carcinoma in a proportion of cases over time [4]. In addition, this long-term chronic infection is capable of causing some extrahepatic manifestations with serious consequences, such as mixed cryoglobulinemia, porphyria cutaneous tarda, type $2 \mathrm{DM}$, thyroid disorders, glomerulonephritis, and lichen planus [10, 11]. Amongst them, type $2 \mathrm{DM}$ is the most notable in recent years.

In 1994, Allison et al. [12] first reported the possible role of HCV in the development of DM. Since then, a higher prevalence of HCV was reported in diabetic pa- tients than nondiabetic subjects in several studies $[3,6$, $10]$, while others $[13,14]$ did not report any difference.

In Iran, there are a few reports with conflicting findings on the seroprevalence of HCV infection among diabetic patients [11], but the presence of HCV-RNA has not been determined. Furthermore, the genotypic pattern of $\mathrm{HCV}$ among HCV-infected diabetic patients is unknown in Iran. The prevalence of type $2 \mathrm{DM}$ among the Iranian population is approximately $8.7 \%[15]$ and is predicted to reach $12.3 \%$ by 2035 [16]. Although the prevalence of DM is high in Iran, there is a big epidemiological gap in estimating the prevalence of HCV among this group of patients. Therefore, further epidemiological studies in different regions are needed to elucidate the association between HCV and DM in Iran. Hence, the objectives of this study were to determine the prevalence and the genotypic pattern of HCV infection among patients with type $2 \mathrm{DM}$ in southern Iran.

\section{Subjects and Methods}

\section{Study Setting and Population}

The Ethics Committee of the Bushehr University of Medical Sciences approved this descriptive cross-sectional study (reference No. B-93-16-17). Consecutive patients with confirmed type 2 DM attending the Diabetic Clinic of the Bushehr University of Medical Sciences for periodical checkups from March to October 2015 were enrolled in this study. The Diabetic Clinic largely provides medical care, treatment, and consultation services for the diabetic patients registered in southern Iran, a vast region located in the north part of the Persian Gulf. Based on the American Diabetes Association criteria, patients were diagnosed as diabetic if there was regular use of oral antidiabetic medications and fasting serum glucose level was $\geq 126 \mathrm{mg} / \mathrm{dL}$ on at least 2 different occasions [17]. The exclusion criteria were the presence of liver cirrhosis, steatohepatitis, fatty liver disease, hepatocellular carcinoma, primary biliary cirrhosis, primary cholangitis, autoimmune hepatitis, hemochromatosis, gestational diabetes, hepatogenous diabetes, type 1 diabetes, pregnancy, thalassemia, hemophilia, hemodialysis, as well as a history of chronic liver diseases, interferon therapy, alcohol consumption, organ transplantation, intravenous drug abuse, blood transfusion, and tattooing.

The clinical information and history were extracted from the medical record of each patient if available or from the patients themselves during enrollment. A total of 556 patients with confirmed type 2 DM (203 males and 353 females) participated in this study. The control group consisted of 733 nondiabetic subjects (257 males and 476 females). The participants were classified into 6 age groups: $26-35,36-45,46-55,56-65,66-75$, and $>76$ years.

\section{Laboratory Measurements}

Blood samples were collected using a clot activator tube with gel separator after at least $8 \mathrm{~h}$ of fasting. Serum levels of fasting blood sugar (FBS), total cholesterol (TCH), triglycerides (TG), alanine transaminase (ALT), and aspartate transaminase (AST) 
Table 1. Seroprevalence of HCV infection according to demographic and biochemical variables among patients with type 2 diabetes in southern Iran, 2015

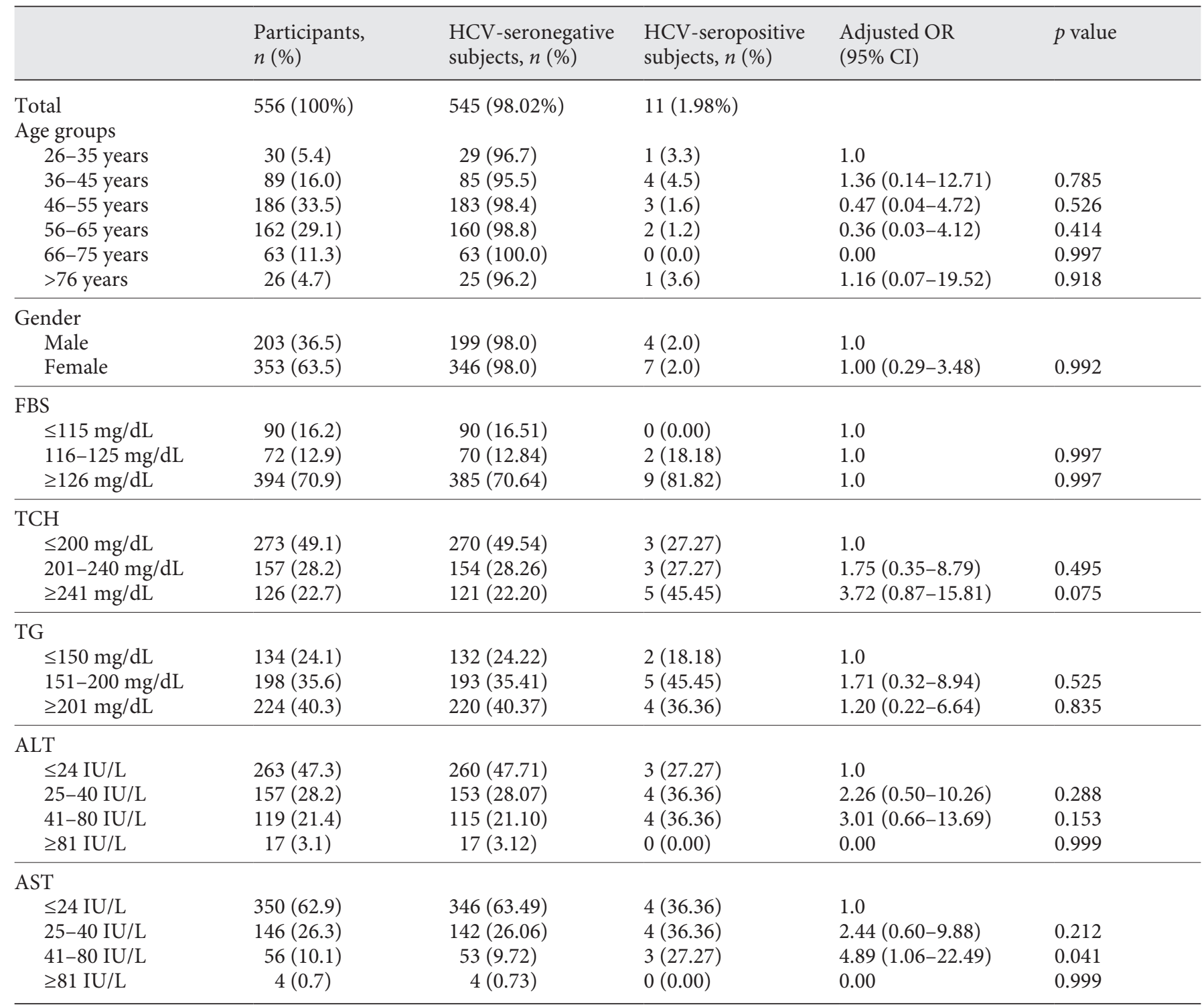

HCV, hepatitis C virus; FBS, fasting blood sugar; TCH, total cholesterol; TG, triglycerides; ALT, alanine transaminase; AST, aspartate transaminase.

were measured using enzymatic colorimetric methods of commercial kits (Bionic, Iran) using a Selectra XL autoanalyzer (Vitalab; Vital Scientific, Dieren, The Netherlands). All the biochemical measurements were done in the Central Laboratory of Bushehr. In addition, each serum specimen was tested in duplicate for the presence of anti-HCV antibodies using an enzyme-linked immunosorbent assay (ELISA) (HCV Ab ELISA kit; DIA.PRO, Milan, Italy). All positive samples were retested and repeatedly reactive samples were labeled seropositive.

The seropositive samples were further tested using a semi-nested reverse transcriptase-polymerase chain reaction (RT-PCR), which amplifies the HCV genome from the $5^{\prime}$-untranslated region ( $5^{\prime}$ UTR) through core. Briefly, HCV RNA was extracted from serum samples using the High Pure Viral Nucleic Acid Kit (Roche, Mannheim, Germany) and was reverse transcribed into cDNA using the SuperScript III cDNA synthesis kit (Invitrogen, Carlsbad, CA, USA) and random primers. Then, cDNA was amplified by semi-nested PCR using outer primers (forward primer derived from the 5'UTR region [-268 to -251]: AGCGTCTAGCCATGGCGT; reverse primer derived from the core region $[+410$ to +391]: ATGTACCCCATGAGGTCGGC), and inner primers (forward primer derived from the $5^{\prime} \mathrm{UTR}$ region [ -268 to -251$]$ : AGC- 
Table 2. Comparisons between $\mathrm{HCV}$-seropositive and $\mathrm{HCV}$-seronegative diabetic patients according to age and biochemical measurements (see Table 1 for abbreviations)

\begin{tabular}{lcccc}
\hline & $\begin{array}{l}\text { All participants } \\
(n=556)\end{array}$ & $\begin{array}{l}\text { HCV-seronegative } \\
\text { subjects }(n=545)\end{array}$ & $\begin{array}{l}\text { HCV-seropositive } \\
\text { subjects }(n=11)\end{array}$ & $p$ value \\
\hline Age, years & $54.39 \pm 11.6$ & $54.5 \pm 11.5$ & $49.0 \pm 13.7$ & 0.356 \\
FBS, mg/dL & $173.64 \pm 73.83$ & $174.12 \pm 74.31$ & $149.73 \pm 38.03$ & 0.326 \\
TCH, mg/dL & $205.1 \pm 51.6$ & $204.65 \pm 51.65$ & $226.55 \pm 46.74$ & 0.160 \\
TG, mg/dL & $202.1 \pm 83.78$ & $202.25 \pm 84.31$ & $196.18 \pm 52.97$ & 0.772 \\
ALT, IU/L & $32.12 \pm 22.61$ & $32.09 \pm 22.69$ & $33.73 \pm 18.53$ & 0.435 \\
AST, IU/L & $24.98 \pm 14.21$ & $24.89 \pm 14.19$ & $29.27 \pm 14.9$ & 0.166 \\
\hline
\end{tabular}

GTCTAGCCATGGCGT, and reverse primer derived from the core region $[+383$ to +364$]$ : CACGTTAGGGTATCGATGAC). The negative and positive controls were included in each round of RT-PCR, and in order to avoid potential contaminations in RT-PCR, precise procedures were taken into consideration [18]. These virological measurements were performed in the Persian Gulf Tropical Medicine Research Center (Bushehr University of Medical Sciences).

\section{Genotyping and Phylogenetic Analysis}

The amplicons were analyzed using agarose gel electrophoresis. The PCR products were then extracted from the agarose gel using the Agarose Gel DNA Extraction Kit (Roche) and were sequenced in both directions (Macrogen Co., Korea). The HCV sequences isolated from diabetic patients were sent to the GenBank sequence database. The Basic Local Alignment Search Tool (BLAST) was used to search the nucleotide sequences of HCV strains available at the nucleotide database of the National Center for Biotechnology Information (NCBI). These sequences and the results of the DNA sequencing were aligned by ClustalW, and the evolutionary distances between the nucleotide sequences of HCV were determined. Then, the phylogenetic tree was constructed by the neighbor-joining method using Molecular Evolutionary Genetics Analysis (MEGA) software version 4.0 (Biodesign Institute, Tempe, AZ, USA), as described previously [19].

\section{Statistical Analysis}

The Statistical Package for the Social Sciences 17 (SPSS Inc., Chicago, IL, USA) was used to perform all statistical analyses. Data were analyzed by descriptive statistics and were presented as frequencies, percentages, and means $\pm \mathrm{SD}$. Categorical data were compared between HCV-seropositive and HCV-seronegative diabetic patients using the $\chi^{2}$ test or the Fisher exact test. The Student $t$ test was used to compare and analyze quantitative data between the two groups. For all analyses, $p$ values $<0.05$ were accepted as significant. Logistic regression analysis was used to evaluate the effect of variables on HCV seropositivity and to determine variables associated with the risk of HCV infection in the diabetic patients, and odds ratios (OR) and 95\% confidence intervals (CI) were computed.

\section{Results}

The mean age of the 556 diabetic patients was $54.4 \pm$ 11.6 years. The majority of the diabetic patients $(62.6 \%)$ were in the age groups 46-55 years and 56-65 years (Table 1). The mean \pm SD (range) levels of FBS, TCH, TG, ALT, and AST were $173.6 \pm 73.8 \mathrm{mg} / \mathrm{dL}$ (71-708), 205.1 $\pm 51.6 \mathrm{mg} / \mathrm{dL}$ (98-391), $202.1 \pm 83.8 \mathrm{mg} / \mathrm{dL}(61-574)$, $32.1 \pm 22.6 \mathrm{IU} / \mathrm{L}(5-224)$, and $25 \pm 14.2 \mathrm{IU} / \mathrm{L}(8-162)$, respectively, in the diabetic patients (Table 2).

The seroprevalence of HCV in the diabetic patients was $1.98 \%(11 / 556)$. The highest rate of seropositivity was observed in those aged $36-45$ years $(4.5 \%, 4 / 89)$ and in those with abnormal FBS levels $(\geq 126)(81.82 \%, 9 / 394)$, whereas the lowest prevalence rate was found in the age group from 66 to 75 years $(0.0 \%)$ and in those with controlled FBS levels $(\leq 115)(0.0 \%)$. Regarding gender distribution, $1.97 \%$ of males $(4 / 203)$ and $1.98 \%$ of females (7/353) were positive for anti-HCV antibodies.

While HCV-seropositive diabetic patients had higher $\mathrm{TCH}, \mathrm{ALT}$, and AST levels than $\mathrm{HCV}$-seronegative diabetic patients, HCV-seronegative diabetic patients had higher FBS and TG levels than the seropositive cases (Table 2). Overall, there were neither significant differences between $\mathrm{HCV}$-seropositive and $\mathrm{HCV}$-seronegative diabetic patients regarding the serum levels of ALT, AST, FBS, TG, and TCH, nor was there a difference in the age distribution or gender distribution. In logistic regression analysis, only AST was significantly associated with HCV seropositivity among diabetic patients (Table 1). Hence, the AST level of 41-80 IU/L was the only significant predictive variable for $\mathrm{HCV}$ seropositivity in the diabetic patients (OR: 4.89; 95\% CI: 1.06-22.49; $p=0.041$ ).

Regarding the presence of HCV RNA in the seropositive serum samples, 7 of $11 \mathrm{HCV}$-seropositive samples were positive in the first round of PCR (Fig. 1), and an- 


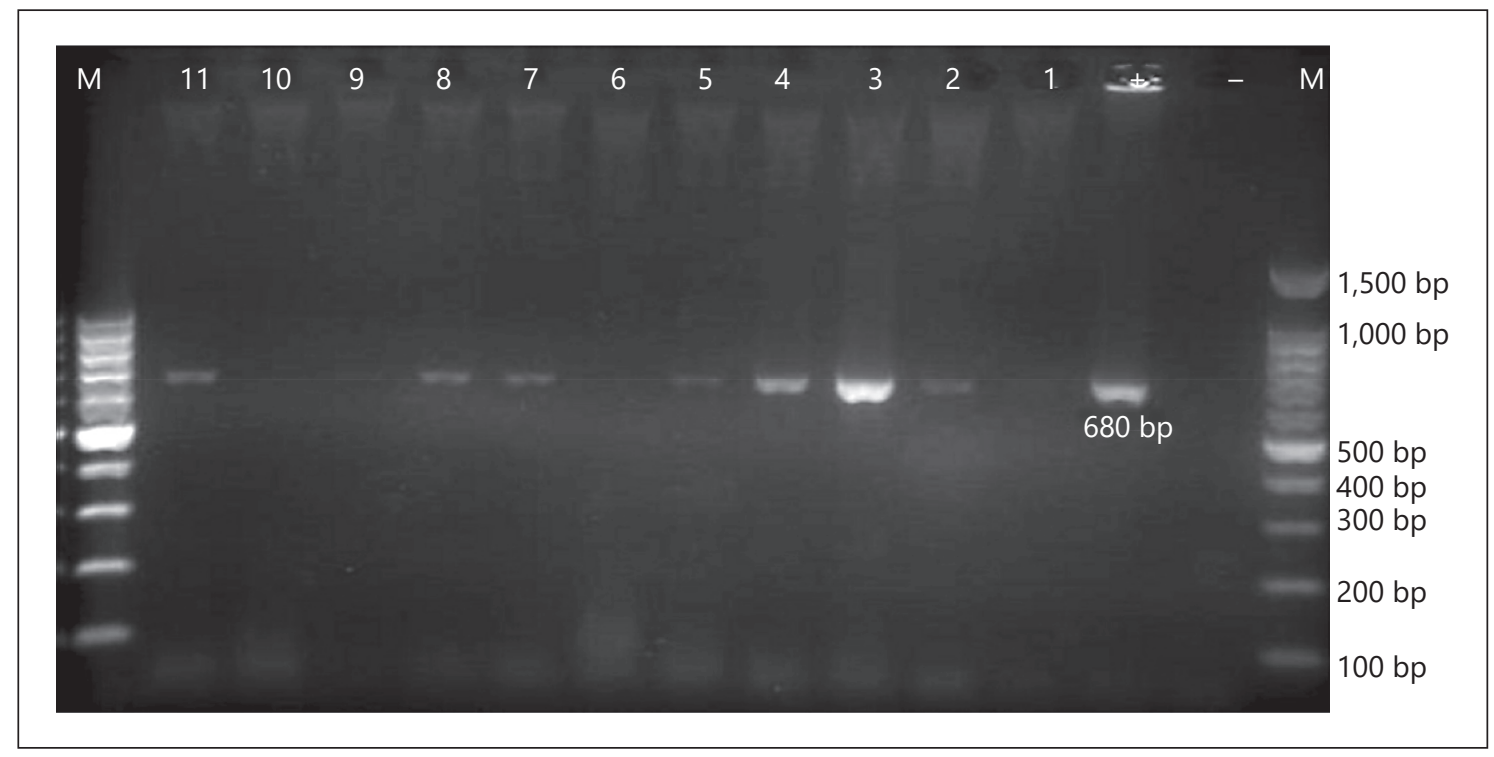

Fig. 1. The first round of RT-PCR amplification of hepatitis $C$ virus RNA extracted from serum samples of HCVseropositive diabetic patients. M, 100-bp DNA ladder; -, negative control; +, positive control; 1-11, amplified product ( $680 \mathrm{bp}$ ) on $2 \%$ agarose gel electrophoresis.

Fig. 2. The second set of semi-nested RTPCR amplification of negative PCR products ( $n=6$ and 10) and weak-positive PCR products ( $n=1$ and 9 ) from first-round PCR. M, 100-bp DNA ladder; -, negative control; +, positive control; $1,6,9$, and 10 , amplified product (580 bp) on $2 \%$ agarose gel electrophoresis.

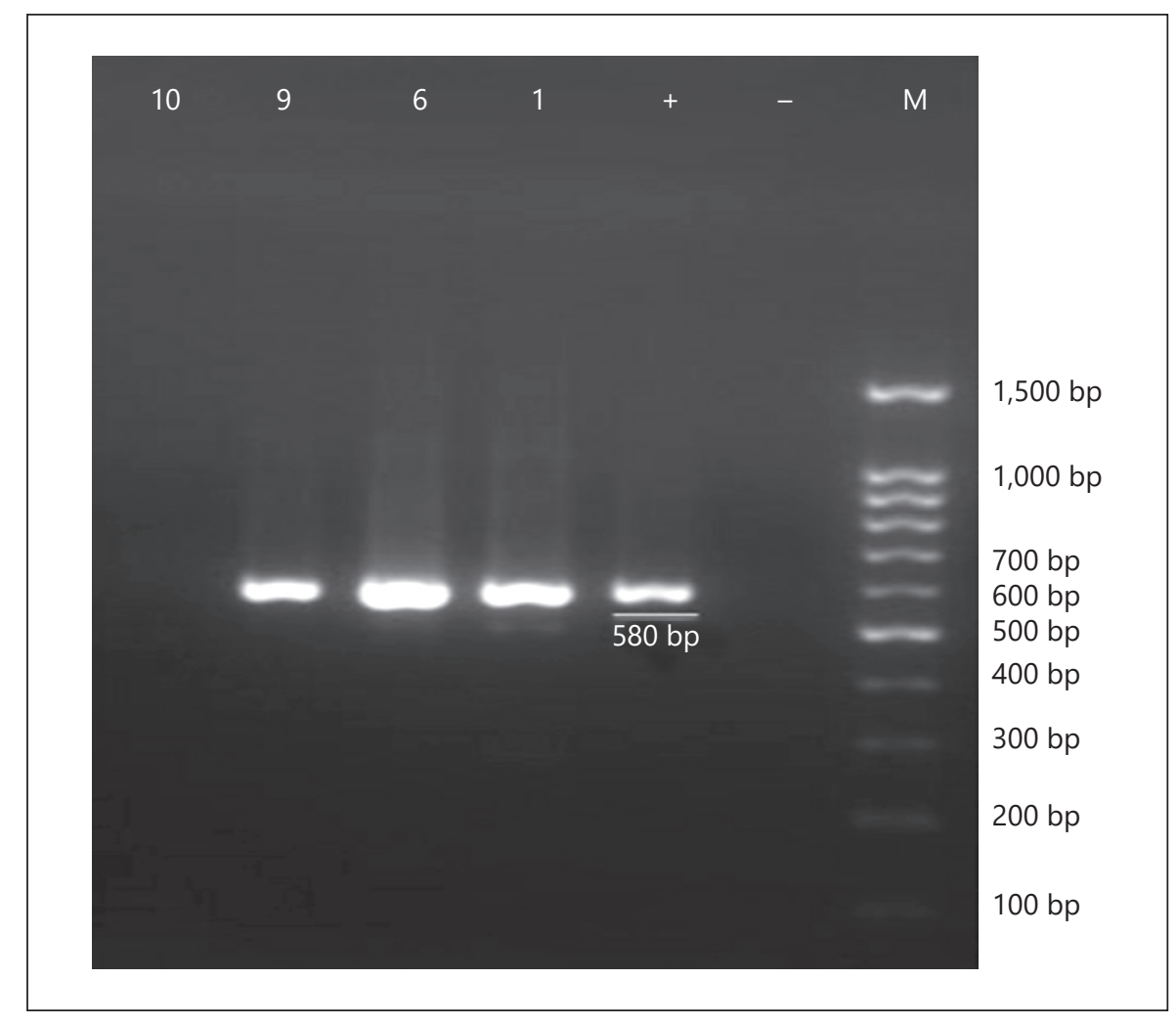




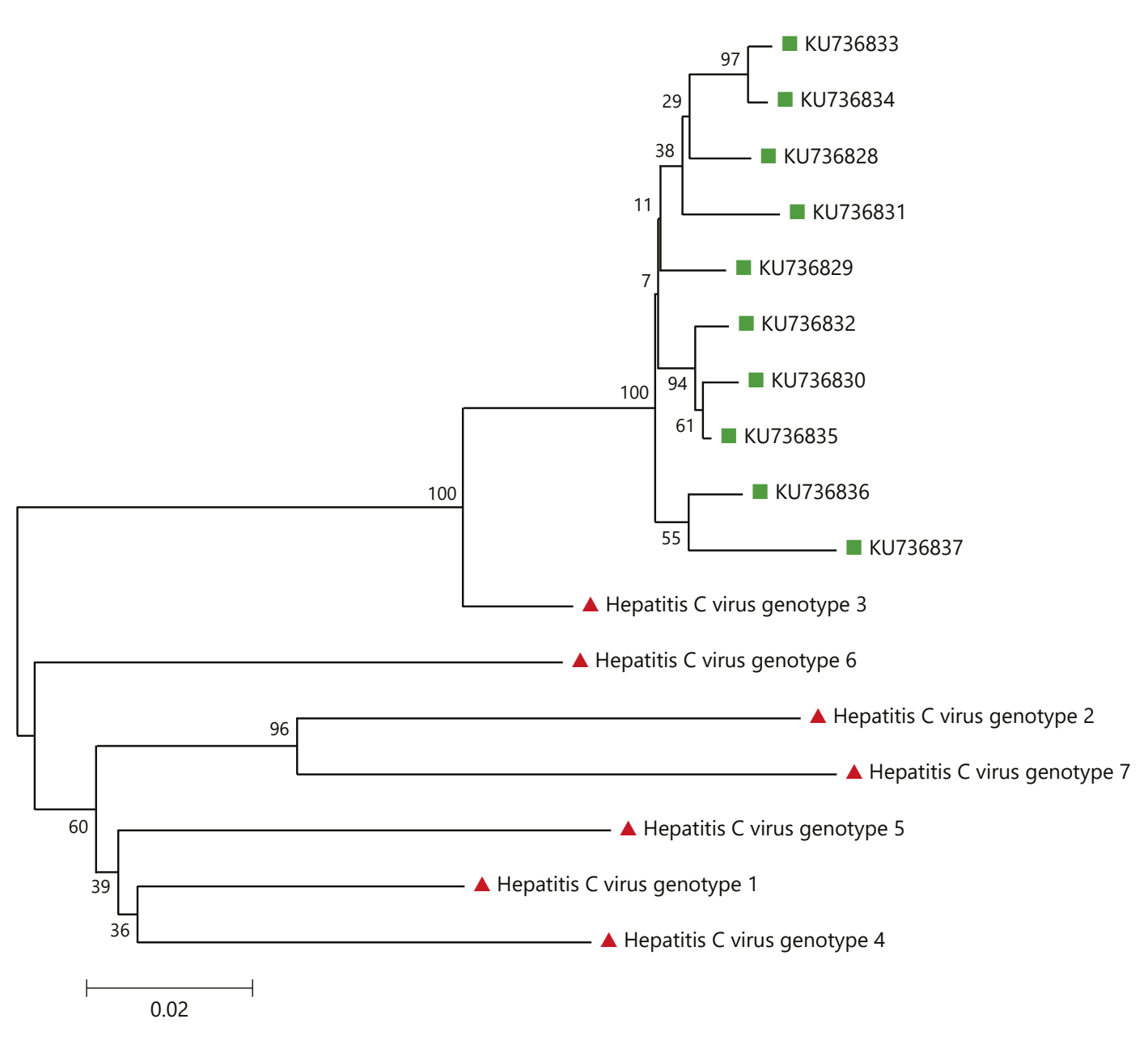

Fig. 3. Neighbor-joining phylogenetic tree based on partial sequences of hepatitis $\mathrm{C}$ virus ( $\mathrm{HCV}$ ) isolates from the serum of 10 patients with type 2 diabetes mellitus in southern Iran, 2015 (KU736828-KU736837). Bootstrap resampling strategy and reconstruction were carried out 1,000 times to confirm the reliabil- ity of the phylogenetic tree. HCV genotype 1 (accession No. NC_004102.1), HCV genotype 2 (accession No. NC_009823.1), HCV genotype 3 (accession No. NC_009824.1), HCVgenotype 4 (accession No. NC_009825.1), HCV genotype 6 (accession No. NC_009827.1), HCV genotype 7 (accession No. EF108306). other 3 samples were found to be positive in the second round of PCR (Fig. 2). Overall, of the $11 \mathrm{HCV}$-seropositive diabetic patients, 10 (91\%) had HCV viremia. The $\mathrm{HCV}$ sequences isolated from diabetic patients were identified as genotype $3 \mathrm{a}$ by sequencing and phylogenetic analysis (GenBank accession Nos. KU736828KU736837) (Fig. 3). Of the 733 nondiabetic controls, 4 $(0.54 \%)$ were positive for anti-HCV antibodies, of which $3(75 \%)$ had HCV viremia with genotype 3 a.

\section{Discussion}

In this study, $1.98 \%$ of patients with type $2 \mathrm{DM}$ had evidence of HCV infection compared to $0.54 \%$ of the nondiabetic controls. Therefore, the prevalence of $\mathrm{HCV}$ infection in the diabetic patients was significantly higher than that in nondiabetic controls $(p=0.032)$. The HCV prevalence of $1.98 \%$ observed in the diabetic patients was approximately 44 times higher than the HCV prevalence of $0.045 \%$ reported in the blood donor population of southern Iran [20]. In addition, the $1.98 \%$ HCV preva- 
lence in this diabetic population was higher than among the blood donors $(0.5 \%)$ and the general population $(0.6 \%)[11,20]$.

The high prevalence of $\mathrm{HCV}$ infection in the diabetic population in this study might be due to the probable role of HCV infection in the development of DM or frequent medical interventions, hospitalization, and blood glucose monitoring $[3,5,6,21]$. The probable role could be due to induction of insulin resistance through destruction of insulin signaling pathways associated with overproduction of proinflammatory cytokines, such as IL-6 and TNF- $\alpha$, in response to HCV infection and direct and/or indirect immune-mediated cytopathic effects of HCV on pancreatic islet cells, which may result in the destruction of $\beta$-cells and subsequently reduced insulin production [4, 21-23]. Insulin resistance presents at the early stages of chronic HCV infectioin, even prior to progression to fibrosis and cirrhosis $[21,22]$.

The nosocomial transmission of HCV seems unlikely in the diabetic population of this study. Since blood glucose monitoring and medical interventions with shared equipments are prohibited in institutional care settings in Iran, and finger stick devices for blood sampling are rigorously changed after every use. In addition, opportunities for sharing diabetic care equipments among multiple patients outside of institutional settings are the least option due to an increase in public awareness regarding the transmission routes of HCV. Even if our diabetic population is considered as a high-risk group for HCV infection, the HCV prevalence of $1.98 \%$ reported in the diabetic patients of the present study is yet lower than those reported among the other high-risk groups in Iran: 50-75\% among intravenous drug users, $13.6 \%$ among hemodialysis patients, $40.8 \%$ among hemophilia patients, and $18 \%$ among thalassemia patients [11]. Furthermore, there was no difference between HCV-seropositive and HCV-seronegative diabetic patients in terms of medical procedures and hospital admissions. It is worth noting that the highest HCV seroprevalence was observed among the diabetic patients aged 26-45 years. If medical interventions were the reason for this high HCV prevalence among the diabetic patients, the HCV seroprevalence rate in diabetic patients would be expected to increase with age due to more parenteral exposures overtime, while it was not the case in our study.

The HCV seroprevalence of $1.98 \%$ in the diabetic population in this study is lower than those reported in previous studies from different parts of the world (1.78-12.1\%) [24]. This might be due to the exclusion of diabetic cases with high-risk behaviors from the study population, which has subsequently resulted in a lower prevalence rate. The effect of some specific HCV genotypes on the development of type $2 \mathrm{DM}$ should also be considered. Some previous studies have reported high frequencies of genotypes 1 and 4 in diabetic patients $[6,25]$. The results of the present study do not support these findings, since genotype 3 a was the only genotype found in our diabetic population. The findings of the present study are in agreement with the genotypic pattern of diabetic patients in the study of Memon et al. [4] and Hui et al. [26]. After genotype $1 \mathrm{a}$, genotype $3 \mathrm{a}$ is the most prevalent genotype in Iran, which is frequently observed among young Iranian patients and intravenous drug users, while genotypes 2 and 4 are uncommon in Iran $[11,27]$. Overall, it is not obvious whether the HCV genotype $3 \mathrm{a}$ observed in the present study is responsible for the occurrence of DM or whether it merely follows the predominant genotypic pattern of HCV in the region. However, this specific genotypic pattern of HCV infection in the diabetic patients of the present study is unlikely to be ascribable to chance alone and, therefore, merits further attention.

In this study, no significant differences in TG, TCH, ALT, and AST levels were found between the HCV-seropositive and the HCV-seronegative diabetic patients, although the $\mathrm{HCV}$-seropositive diabetic patients tended to have higher ALT, AST, and TCH levels but lower TG and FBS levels than the HCV-seronegative diabetic patients. On the other hand, Laloo et al. [28] and Akbar et al. [23] demonstrated that HCV seropositivity among diabetic patients is associated with raised ALT and AST levels. This discrepancy between our results and those of previous studies might be due to some differences in the duration of diabetes, type of treatment, severity of liver diseases, and level of liver enzymes among diabetic patients in different studies.

Furthermore, there was no difference in gender distribution between the HCV-seropositive and HCV-seronegative diabetic patients, although diabetes was more prevalent in females than males. This finding is in agreement with the report of Olokoba et al. [3], but is in disagreement with the findings of Jadoon et al. [10] and Laloo et al. [28]. These variations in gender distribution of HCV infection among diabetic patients in different studies might be due to some differences in the predominant routes of transmission, social life styles, and risk behavior patterns between these two genders in different parts of the world.

Overall, in this study, HCV seropositivity among the diabetic patients was not statistically associated with serum levels of FBS, ALT, AST, TG, TCH, and AST as well 
as age and gender distribution. Therefore, the possibility of the presence of chronic HCV infection should be considered in all diabetic patients regardless of the biochemical measurements. Nevertheless, logistic regression analysis revealed that the chance of having an AST level of 41-80 IU/L was almost 4 times higher in the HCV-seropositive diabetic patients than in the $\mathrm{HCV}$-seronegative patients. This is an expected finding given the presence of chronic viral hepatitis among the HCV-seropositive diabetic patients. However, the relationship between AST levels of 41-80 IU/L and HCV seropositivity in diabetic patients should be considered with caution, because $9.72 \%$ of the HCV-seronegative diabetic patients also had AST levels of 41-80 IU/L. The incidence of HCV-related insulin resistance is independent of the stage of liver disease. On the other hand, HCV-related insulin resistance and type $2 \mathrm{DM}$ accelerate the development of liver fibrosis, cirrhosis, and hepatocellular carcinoma, while HCV clearance following antiviral treatment is associated with improved insulin resistance and reduced incidence of type 2 DM $[9,29,30]$.

A review of the national literature indicates that there are conflicting results on the associations between HCV infection and type $2 \mathrm{DM}$ in different parts of Iran [11]. This discrepancy between the results of these studies, including our own, prevent us from reaching a consensus on the relationship between these two chronic diseases among Iranian patients. Therefore, longitudinal studies at national level are needed to clarify this issue more precisely.

This study has its strengths and limitations. It is the first study of this kind in southern Iran, and the first report on the genotypic pattern of $\mathrm{HCV}$ infection among diabetic patients in Iran. Furthermore, consecutive recruitment of patients with confirmed type $2 \mathrm{DM}$ has increased generalizability of the results to the diabetic pop- ulation of this region. While the most important concern with this study is the cross-sectional design of the study, which disables us from establishing a definite relationship between HCV infection and type $2 \mathrm{DM}$. Therefore, whether type $2 \mathrm{DM}$ increases the occurrence of HCV infection or HCV triggers the onset of type $2 \mathrm{DM}$ remains to be determined in the diabetic population of southern Iran. However, the exclusion of diabetic cases with highrisk behaviors from our study population may support the idea that HCV infection most likely has an effect on the development of type $2 \mathrm{DM}$, but prospective studies including $\mathrm{HCV}$-infected patients at the beginning of $\mathrm{HCV}$ infection are required to determine the possible role of HCV infection in the development of type $2 \mathrm{DM}$.

\section{Conclusion}

In this study, the prevalence of HCV infection in diabetic patients in southern Iran was high, and it was not associated with biochemical parameters. Genotype 3a was the only genotype found in the diabetic population of this study, and all the HCV-infected diabetic patients were unaware of the infection due to the asymptomatic nature of their chronic HCV infection. Therefore, screening of all diabetic patients for HCV infection should be recommended to prevent serious consequences associated with the coexistence of these two chronic diseases in the long run.

\section{Acknowledgments}

The authors would like to acknowledge the financial support from the Deputy Research and Affairs of the Bushehr University of Medical Sciences (grant No. 4365) and the staff members of the Central Laboratory of Bushehr for technical assistance.

\section{References}

$>1$ American Diabetes Association: Diagnosis and classification of diabetes mellitus. Diabetes Care 2010;33:62-69.

2 World Health Organization: Diabetes, WHO Fact Sheet 2016 http://www.who.int/mediacentre/factsheets/fs312/en/ (accessed June 17, 2016).

3 Olokoba $\mathrm{AB}$, Badung LH, Abdulrahman MB, et al: Hepatitis $C$ virus infection in Nigerians with diabetes mellitus. Am J Sci Ind Res 2010; 1:135-138.

\footnotetext{
4 Memon MS, Arain ZI, Naz F, et al: Prevalence of type 2 diabetes mellitus in hepatitis $\mathrm{C}$ virus infected population: a Southeast Asian study. J Diabetes Res 2013;2013:539361.

5 Negro F, Alaei M: Hepatitis C virus and type 2 diabetes. World J Gastroenterol 2009;15: 1537-1547.

$\checkmark 6$ Chehadeh W, Kurien SS, Abdella N, et al: Hepatitis $\mathrm{C}$ virus infection in a population with high incidence of type 2 diabetes: impact on diabetes complications. J Infect Public Health 2011;4:200-206.
}

7 Lonardo A, Adinolfi LE, Petta S, et al: Hepatitis $\mathrm{C}$ and diabetes: the inevitable coincidence? Expert Rev Anti Infect Ther 2009; 7: 293-308.

$>8$ Ballestri S, Nascimbeni F, Romagnoli D, et al: Type 2 diabetes in non-alcoholic fatty liver disease and hepatitis $\mathrm{C}$ virus infection-liver: the "musketeer" in the spotlight. Int J Mol Sci 2016;17:355. 
-9 Lonardo A, Ballestri S, Guaraldi G, et al: Fatty liver is associated with an increased risk of diabetes and cardiovascular disease - evidence from three different disease models: NAFLD, HCV and HIV. World J Gastroenterol 2016;22:9674-9693.

10 Jadoon NA, Shahzad MA, Yaqoob R, et al: Seroprevalence of hepatitis $\mathrm{C}$ in type 2 diabetes: evidence for a positive association. Virol J 2010;7:304.

$>11$ Taherkhani R, Farshadpour F: Epidemiology of hepatitis $\mathrm{C}$ virus in Iran. World J Gastroenterol 2015;21:10790-10810.

$\checkmark 12$ Allison ME, Wreghitt T, Palmer CR, et al: Evidence for a link between hepatitis $\mathrm{C}$ virus infection and diabetes mellitus in a cirrhotic population. J Hepatol 1994;21:1135-1139.

$\checkmark 13$ Costa LM, Mussi AD, Brianeze MR, et al: Hepatitis $\mathrm{C}$ as a risk factor for diabetes type 2: lack of evidence in a hospital in central-west Brazil. Braz J Infect Dis 2008;12:24-26.

14 Gulcan A, Gulcan E, Toker A, et al: Evaluation of risk factors and seroprevalence of hepatitis $\mathrm{B}$ and $\mathrm{C}$ in diabetic patients in Kutahya, Turkey. J Investig Med 2008;56:858-863.

15 Esteghamati A, Meysamie A, Khalilzadeh O, et al: Third National Surveillance of Risk Factors of Non-Communicable Diseases (SuRFNCD-2007) in Iran: methods and results on prevalence of diabetes, hypertension, obesity, central obesity, and dyslipidemia BMC Public Health 2009;9:167.
16 Guariguata L, Whiting DR, Hambleton I, et al: Global estimates of diabetes prevalence for 2013 and projections for 2035. Diabetes Res Clin Pract 2014;103:137-149.

17 Alberti KG, Zimmet PZ: Definition, diagnosis and classification of diabetes mellitus and its complications. Part 1: diagnosis and classification of diabetes mellitus. Provisional report of a WHO consultation. Diabet Med 1998; 15 : 539-553.

18 Kwok Sa, Higuchi R: Avoiding false positives with PCR. Nature 1989;339:237-238.

19 Taherkhani R, Farshadpour F, Makvandi M, et al: Determination of cytomegalovirus prevalence and glycoprotein B genotypes among ulcerative colitis patients in Ahvaz, Iran. Jundishapur J Microbiol 2015;8:e17458.

20 Farshadpour F, Taherkhani R, Tajbakhsh S, et al: Prevalence and trends of transfusiontransmissible viral infections among blood donors in south of Iran: an eleven-year retrospective study. PLoS One 2016;11:e0157615.

21 Ali S, Abera S, Mihret A, et al: Association of hepatitis $C$ virus infection with type II diabetes in Ethiopia: a hospital-based case-control study. Interdiscip Perspect Infect Dis 2012; 2012:354656.

22 Rouabhia S, Malek R, Bounecer H, et al: Prevalence of type 2 diabetes in Algerian patients with hepatitis $\mathrm{C}$ virus infection. World J Gastroenterol 2010;16:3427-3431.
23 Akbar DH, Siddique AM, Ahmed MM: Prevalence of type-2 diabetes in patients with hepatitis $C$ and $B$ virus infection in Jeddah, Saudi Arabia. Med Princ Pract 2002;11:82-85.

24 Lecube A, Hernandez C, Genesca J, et al: Glucose abnormalities in patients with hepatitis $\mathrm{C}$ virus infection: epidemiology and pathogenesis. Diabetes Care 2006;29:1140-1149.

25 Moucari R, Asselah T, Cazals-Hatem D, et al: Insulin resistance in chronic hepatitis C: association with genotypes 1 and 4, serum HCV RNA level, and liver fibrosis. Gastroenterology 2008;134:416-423.

26 Hui JM, Sud A, Farrell GC, et al: Insulin resistance is associated with chronic hepatitis $\mathrm{C}$ and virus infection fibrosis progression. Gastroenterology 2003;125:1695-1704.

27 Taherkhani R, Farshadpour F: Lurking epidemic of hepatitis $\mathrm{C}$ virus infection in Iran: a call to action. World J Hepatol 2017;9:10401042.

28 Laloo D, Walke P, Bhimo T, et al: Seroprevalence of hepatitis $\mathrm{C}$ infection in type 2 diabetes mellitus. Indian J Endocrinol Metab 2015;19: 296-299.

29 Vanni E, Bugianesi E, Saracco G: Treatment of type 2 diabetes mellitus by viral eradication in chronic hepatitis C: myth or reality? Dig Liver Dis 2016;48:105-111.

30 Negro F, Forton D, Craxi A, et al: Extrahepatic morbidity and mortality of chronic hepatitis C. Gastroenterology 2015;149:13451360 . 